\title{
Significant Personal Disclosure: exploring the support and development needs of HE tutors engaged in the emotion work associated with supporting students
}

\section{Jan Huyton}

University of Wales Institute, Cardiff, UK

\begin{abstract}
This paper explores emotion work taking place in the private and personalised space of supportive encounters between individual students and tutors. An emotional labour framework is used to consider the effects on tutors of work intensification and performance requirements in learning relationships with students. The paper goes on to consider professional role boundaries and staff development, training and support. The paper concludes that institutions need to recognise the existence of emotion work as a pedagogy in the context of student support or learning development. Failure to do so will have detrimental effects on tutors and the service they provide to students.
\end{abstract}

Keywords: emotion work; staff development; therapeutic turn

\section{Introduction}

'Emotion work' is most likely understood by colleagues in the learning development community as working with students on recognising and managing their emotions in order to facilitate transformative learning. Indeed whilst many emotional states exist outside the terms of pedagogic engagement, their impact on a student's ability to learn can be significant (Brockbank and McGill, 2006; Beard et al, 2007). 'Emotion work' has been defined elsewhere as 'work that transforms the emotional state of others', thereby having a role in the development of areas such as commitment, enthusiasm and well-being (Centre for Research into Emotion Work [on-line]). Hochschild (2003: 7) considers 'emotion work' to be largely synonymous with 
'emotional labor' [sic]: the latter occurring in a waged workplace context in which it has 'exchange value'; the former occurring in private space wherein it has 'use value'. Most definitions of 'emotion work' include the concept of management of emotions, usually in face-to-face individual encounters. 'Emotional labour' carries additional connotations that can be located in a critical theoretical framework, and problematises the commercialisation of human feeling and the exploitation of human emotion in a range of workplace contexts. A semantic debate would be helpful here, as any definition of terms is likely to be contestable, but that would be beyond the scope of this paper.

Mortiboys (2002: 28) comments that 'significant personal disclosure in public on the part of students is rarely appropriate in courses in higher education'. My exploration in this paper concentrates on emotion work taking place in the private and personalised space of supportive encounters between individual students and tutors. The role of the tutor in this context can be to help students 'develop a better understanding of the energies and challenges involved in coming to terms with studying' (Beard et al, 2007: 250). Thus the student support interactions referred to in this paper are viewed as constituent features of learning development.

I will focus specifically on the extent to which the management of emotions can shift from a positive force for enriching institutions and the lives of individuals (Mortiboys, 2002) into emotional labour or unsupported emotion work which can have damaging effects on the well-being of practitioners and the ethos and quality of student support. I will refer to literature that considers the nature of emotion work or emotional labour in the context of supporting learners in $\mathrm{HE}$, and make brief reference to literature on counselling supervision. I will also draw on early data (the first 66 respondents to an electronic survey distributed to a range of HE lecturers and tutors in the UK) from my ongoing research project on the experiences of lecturers engaged in student support, and feedback from participants at an ALDinHE conference workshop where an earlier version of this paper was presented.

The paper is divided into two sections. The first section uses emotional labour as a framework for analysis and considers the effects on tutors of work intensification and performance requirements in learning relationships with students. The second 
section is developed around professional role boundaries and staff development, training and support. The paper concludes that institutions need to recognise the existence of emotion work as a valid strand of pedagogical practice in the context of student support or learning development. Failure to do so will have detrimental effects on tutors and the service they provide to students.

Account will be taken of recent debates prompted by Ecclestone (2004); Furedi (2004); Ecclestone et al (2005); and Ecclestone and Hayes (2009) who have poured scorn on what they believe to be a therapeutic turn in education. Ecclestone et al (2005) and Ecclestone and Hayes (2008) deride the idea of emotional well-being in learning and teaching, claiming it works with the assumption that students are diminished subjects, vulnerable and damaged by everyday experiences and unable to exercise agency and resilience. Mortiboys has entered the debate by defending his position on teaching with emotional intelligence, explaining that the use of emotional intelligence should not be equated with a generalised assumption of vulnerability (Newman, 2008). In a similar vein I take issue with Ecclestone et al (2005) who caution against expressions of concern for the emotional well-being of tutors.

\section{The effects on tutors of work intensification and performance requirements in learning relationships with students}

It has been suggested that tutors tend to be viewed by students as role models, which places on them a responsibility to be enthusiastic, confident and happy people (Lawrence, 2000). Anecdotally, it seems likely that most tutors can recall having 'offdays', times of emotional depletion, tiredness, distress or anger. At such times professional display rules can be employed in order to give a good service to students. Thus it is likely that practitioners will, on occasions, need to marshal the skills to communicate enthusiasm and confidence, when perhaps these are not genuinely felt. This could be regarded as managing one's emotional display in order to influence others, and hints at the kind of emotional performance requirement or professional display rules that characterise Hochschild's definition of emotional labour. Some participants at the ALDinHE workshop suggested that if the result of an inauthentic but effective performance of enthusiasm and confidence is a positive 
outcome for the student and the tutor, then this should not necessarily be seen as problematic.

I would agree that occasional recourse to potentially inauthentic performance of professional display rules could be viewed as a key factor in the consistent delivery of effective learning support. My concern relates to situations in the HE workplace where inauthentic displays of enthusiasm, confidence or simply caring about the fate of students become the norm for tutors. Hochschild (2003: 90) refers to 'a principle of emotive dissonance' whereby a separation of display and feeling is hard to sustain over a long period and can sometimes lead to estrangement from true feeling. A study of university lecturers (Ogbonna and Harris, 2004) found situations in which lecturers describe 'faking it' as a mechanism for coping with the emotional demands of the role:

'I don't think it's feasible for us to care about every single student. Ten years ago I knew their names and faces - today it's a miracle if I can remember what degree they're doing. Pretending to remember their problems and faking concern is just a coping response.' (Lecturer, new university, aged 39).

'It's about image — creating a brand of "me"... I have no problem with faking concern about students if it gets me another increment [point].' (Lecturer, new university, aged 27)

(Ogbonna and Harris, 2004: 1197).

It seems that inauthentic performance had become normalised behaviour for a number of practitioners in the Ogbonna and Harris study. The causal factors are analysed in an emotional labour framework which places work intensification (resulting from the bureaucratisation and managerialisation of $\mathrm{HE}$ ) as the key causal factor. There is no suggestion that inauthenticity has become normalised as a deliberate student support technique, but the findings do suggest that general work intensification in a number of areas has left many lecturers feeling depleted to the extent that it becomes difficult to evoke a genuine caring response.

Ogbonna and Harris set out to explore emotional labour in the context of work intensification. I am seeking more specifically to explore with tutors the nature and 
extent of emotion work in supportive encounters with individual students, and to identify associated implications for tutors and organisations. Respondents to my electronic survey tended to be lecturers with considerable experience in emotion work and learning support. More than $77 \%$ had been in a student support role for 5 years or more, and $80 \%$ described their role as a combination of pastoral and study support. Approximately 69\% were able to recall particularly challenging student support encounters. These included dealing with student experiences of rape, domestic violence, bereavement, suicidal thoughts and a range of mental health scenarios. One respondent described such situations as:

bigger and more significant events than my training had prepared me for.

Ecclestone et al (2005) comment from a more political perspective. They find there is pressure on tutors to intensify emotional labour to conform to enhanced expectations of a demonstration of care towards students. A focus on emotional well-being is, they suggest, a means of overcoming student disaffection from the curriculum and educational experience. This view concurs with CREW [on-line] who define emotion work as a means of ensuring the 'enthusiasm, commitment and compliance' of 'customers and clients'. A number of respondents to my electronic survey mentioned the role student support plays in delivering favourable retention and achievement rates for audit compliance. Responses such as:

It appears to be something you need to 'get on with' and there is an expectation that this will be carried out - especially with pressures related to retention and achievement.

In our institution we have a big widening participation push and ... it seems an unwritten expectation that the support is given to ensure that retention and achievement is kept at what the institution thinks is a suitable level.

indicate an institutional focus on retention and achievement as measures of the success of student support activity. This could be seen as having resonance with Hochschild (2003) who found that a commercial organisation has expectations that its customer service staff will utilise emotional display rules in order to manage the 
feelings and behaviour of customers. It is perhaps evidence that managerialism and marketisation have been sufficiently powerful to displace notions of curriculum and pedagogy (Walker, 2002: 43).

Many participants at the ALDinHE workshop expressed the view that the intensification of workloads, combined with a lack of time, space and resources (for reflection on practice, debriefing, offloading or professional supervision), had resulted in some tutors feeling overwhelmed by the emotional content of student support work. Some had managed to negotiate for themselves formal or informal support within the institution, but others had no support mechanisms in place. This is reflected in my survey responses; almost $70 \%$ reported having experienced occasions when they needed more support such as de-briefing or offloading after a difficult session with a student. Respondents reported that they draw on support from colleagues (86\%) and their own professional experience (70\%). Support from institutional resources was more limited (line manager, 38\%; professional supervision, 21\%). Ogbonna and Harris (2004) noted attempts by lecturers to retreat to their offices described as 'havens' or 'refuges' as a means of escaping from the emotional demands of the job, but the effectiveness of this technique was frequently undermined by interruptions.

There appear to be consequences for the well-being of tutors engaged in emotional aspects of student support. Certainly there are implications for higher education administration, leadership and staff development which relate to the way in which working environments encourage authenticity (Kreber et al, 2007). Ecclestone et al (2005) take issue with such expressions of concern about the emotional well-being of tutors. Their objections are grounded on the risk that emotional 'care' will become more important than material support or radical professional change.

My own early research findings indicate that it is not the nature of emotion work which some tutors find stressful and burdensome, but the volume of work and a lack of preparation for the role. This shifts the problem to an institutional rather than an individual level, and problematises excessive workloads and ineffectual staff development instead of pathologising students and tutors as excessively needy individuals. 
In the next section I will argue that institutions and practice communities have both a professional and an ethical duty to ensure tutors are appropriately supported in emotion work that is integral to developing supportive learning relationships with students. Whilst I accept a concern that emotional care might displace more radical responses, I will argue from a more emancipatory perspective that as practitioners we can and should exercise individual and collective agency to achieve the fundamental professional and practice change required to ensure working conditions respond appropriately to the nature of contemporary learning relationships.

\section{Professional role boundaries and staff development, training and support}

Earwaker (1992) is frequently cited in scholarly work on the topic of supporting students. His work highlights the extent to which tutors may straddle 'a most interesting divide' (1992: vii) between student support and other academic roles. These observations remain pertinent despite the passage of more than fifteen years since they were made.

Whilst being clear that 'tutors do not have to move into a counselling role in order to help their students' (1992: 131), Earwaker emphasises that learning support must encompass a form of pedagogy that recognizes and takes account of the effects of personal change on learners. Earwaker's proposal (1992: 134) is that we develop 'a shared sense of purpose which binds together all our teaching, learning and helping into a coherent educational philosophy'. This resonates with Rogers' idea of unified learning (1980) which melds the cognitive, experiential and affective.

Earwaker was clear that learning support, whilst encompassing support for students undergoing personal change, should remain distinct from counselling and other forms of professional emotional support. In 1995, however, Easton and Van Laar reported on a survey conducted in a post 1992 university in which 97\% of a sample of 231 tutors reported having 'counselled' one or more distressed students in the year preceding the survey. Approximately three-quarters said that they had 'counselled' students experiencing examination, career or financial problems, and more than half 
had dealt with health, accommodation or self-confidence problems. More than $30 \%$ said that they had 'counselled' students about depression, relationships or homesickness, and approximately one in five had 'counselled' students about loneliness.

Whilst acknowledging they have no reference point for respondents' use of the term 'counselling', Easton and Van Laar note that professionals working with client problems such as loneliness or depression would usually, according to professional and ethical guidelines, have in place appropriate training, support and supervision. These are considered essential requirements in the avoidance of stress, dissatisfaction or 'burnout', yet very few survey respondents had received training in these areas. This led Easton and Van Laar to highlight the importance of formalised training and support for higher education practitioners in order to help avoid tutor distress or dissatisfaction when working with distressed students.

Easton and Van Laar cautioned that their results could not be generalisable. Their response rate of $41 \%$ is perhaps an indication that those minded to respond were likely to have an interest in supporting students, which is also likely to be a characteristic of my electronic survey sample. Whilst neither study can claim that the data indicate levels of engagement with student support amongst HE tutors in the UK, we are given a useful insight into the experiences of those tutors who are actively engaged in supporting individual students.

As Crossman (2007: 325) points out, the issue is not related to expectations of professional behaviour in which we externalise the emotional content of interactions with students. It is about how we learn to view the significance of emotions and relationships in making professional and ethical decisions about our supportive interactions. 'Higher education institutions would do well to consider further how teaching and learning occurs in a particular context in which individuals interact, conduct relationships and experience feelings about those relationships'.

Habley (2000) notes from research on universities in the USA that only one third of campuses provided training in academic advising, and less than one quarter required staff to undergo such training. The majority of training programmes focused only on the communication of factual information and little time was devoted to relationship 
skills. Similarly, Grant (2006) notes that a student's declining academic performance may be a symptom of personal concerns or mental health difficulties, which some practitioners may not be sufficiently skilled or experienced to recognise. This resonates with my electronic survey findings which identified only $10 \%$ of respondents who felt they had received comprehensive and adequate training for the student support role. The most frequent experience was limited training with needs largely met (38\%). 30\% had received no training at all, or extremely limited and inadequate training. Ironically Earwaker (1992: 46) was reporting similar findings in the early 1990s. Tutors were dealing with 'acute personal distress' relating to student difficulties including family violence, sexual harassment, divorce, ill- health and unplanned pregnancy, many tutors feeling overwhelmed or out of their depth at times.

It is claimed that the 'widening access agenda' has brought us new learners, often from non-traditional backgrounds, for whom learning support will encompass a range of areas including confidence-building, finance, lack of personal or family support, and academic difficulties (Tholstrup, 1999; Simon Frank, 2000; Wootton, 2006). Claims that 'widening access' has resulted in a significant change in the nature and volume of student support needs implies a deficit model for some students and indicates a largely remedial approach (Earwaker, 1992; Marr and AynsleySmith,2006). Although I cannot concur fully with the notion of a therapeutic turn in learning and teaching (Ecclestone, 2004; Furedi, 2004; Ecclestone et al, 2005; Ecclestone and Hayes, 2009) I feel there is some merit in the argument that an overemphasis on the individual runs the risk of overlooking social and interpersonal dimensions of identifying and addressing emotional needs of both tutors and students as part of the learning and development process.

Ecclestone (2004: 118) is concerned about the effects of 'therapeutic pedagogy' which can mean that students and educators will come to believe students from 'marginalised' or 'disaffected' groups in society will be 'unable to cope without support'. Ecclestone's message has received a mixed reaction from practitioners who work in student support roles. There is merit in the view that students from 'marginalised' or 'disaffected' backgrounds should not be singled out as being unable to cope, and it would be better to argue that all students might potentially be in need 
of support (Marr and Aynsley-Smith, 2006). Indeed Earwaker (1992: 45) reminds us that the concept of personal tutoring has its origins in the elite institutions of medieval Oxford and Cambridge where undergraduates would be allocated a tutor to monitor and address their pastoral needs. Thus an over-emphasis on 'widening access' as the origin of an increase in the pastoral work of tutors, thereby labelling some social groups as particularly needy, is not only damaging but is potentially incorrect. It is likely that a perceived intensification of student support needs can be linked with the fact that the continued increase in student numbers has not been accompanied by a commensurate increase in resources to maintain teaching and tutoring relationships (Macfarlane, 2004).

Earwaker's position on the need for a distinct boundary between the Rogerian notion of learning support that encompasses both the emotional and the cognitive, and the act of counselling as a specific activity to be undertaken by trained professionals, indicates the suitability of a referral model. Such an approach appears to have been accepted by the number of HE institutions that increasingly offer counselling, mental health and other professional services via a centralised student support facility. This can be risky in that institutions may assume they have effectively externalised emotion work out of learning and teaching interactions, thereby removing the need to build in support for tutors engaged in emotion work.

Owen's research (2002) into the effectiveness of this model found that it posed difficulties in that students would probably be deep into explaining their problems before the need for referral became apparent, and it is often difficult to disentangle a learning support issue from a personal problem in any case. So the 'professional model' does not mean that tutors no longer listen to students' emotional problems. There can be institutional expectations, however, that those who feel emotionally exhausted from listening to students' problems should work harder at their role boundaries and make more referrals. This may well be true in some cases, but failure to make an appropriate referral often arises out of institutional failure to offer staff development that would enhance tutors' skills in this area of practice.

There is strong evidence from my electronic survey that tutors from occupational backgrounds such as professions allied to medicine, social work, youth work and 
counselling have drawn on their previous skills and experience to recognise role boundaries and make appropriate and sensitive referrals. Tutors with little or no experience in emotion work may be without a frame of reference to recognise the boundary between a therapeutic and a pedagogic intervention, the nature of which can be nebulous even for the most experienced practitioners.

It should also be acknowledged that professional supervision for counsellors and others in similar professions includes the encouragement to reflect on and evaluate practice, and to remain in a learning zone rather than a panic or comfort zone (Hawkins and Shohet, 2007). The literature on counselling supervision highlights the importance of facilitated space for reflection and exploration of professional boundaries (for example: Brady et al, 1985; Hawkins and Shohet, 2007). Wilkins (1997) purports that personal and professional development is about much more than meeting organisational requirements (which in the case of learning support might mean meeting performance targets for retention and academic achievement). Developing and maintaining good practice should include rest and relaxation as well as making efforts to improve and deepen knowledge of practice. He goes on to emphasise a professional obligation to take measures to manage stress and 'burnout' caused by our own personal experiences, the demands of our organisations, and the behaviour of some of our 'clients'. The introduction of professional supervision for tutors engaged in student support work would enhance the quality and effectiveness of practice, facilitating appropriate consideration of role boundaries and the ability to work on avoiding 'burnout'.

I have already indicated that the majority of respondents to my survey drew on informal support from colleagues when dealing with particularly challenging emotion work scenarios. Concerns were also expressed about the fact that space to meet with colleagues was being eroded by workload pressures. This resonates with Ogbonna and Harris's findings where many lecturers felt their own needs had become overlooked in the race to achieve organisational imperatives, meaning the level of supportive interaction between colleagues had diminished over time:

'Years ago this was a dynamic place - everybody in and out of everybody else's office. If you had a problem you talked about it, worked the problem 
through. Today everybody's out for themselves — nobody wants to show weakness. We're all individuals within a partitioned box!' (Lecturer, new university, aged 42)

(Ogbonna and Harris, 2004: 1192).

Carroll and Walton (1997: 2) describe the importance of context in determining acceptable behaviour rules. The literature on emotional labour refers to attitudes or standards towards basic emotional responses, the appropriateness of which are defined by society or groups within society. Forms of emotional expression can be either legitimised or overlooked, depending on the institutional, group or individual context (Stearns and Stearns, 1985; Stearns, 1989; Morris and Feldman, 1996; Fisher and Ashkanasy, 2000). Fineman (2003: 138) writes: 'It is a particular irony that those who deal professionally with other people's stresses... often find it difficult to voice their own stresses.' He describes this as 'the stress trap of professionalism, where professional mystique is to be preserved, regardless of personal cost' (2003: 139).

This resonates with Crossman (2007) who advocates creating spaces for reflection and rethinking teaching and learning practices as a basis for training and professional development planning. This might help create a change to an organisational culture in which practitioners feel more comfortable with using reflective practice as an opportunity to explore their own support needs arising out of emotional interactions with students. Hawkins and Shohet (2007: 3) suggest there is a tendency to 'get on with it', or 'keep one's head down', an attitude with which organisations and individuals often collude 'for a variety of reasons, including external pressures and internal fears of exposing one's own inadequacies'. Whilst Ecclestone's emphasis on the dangers of overlooking the radical and the political should be welcomed, the manner in which the 'therapeutic turn' is expressed brings its own dangers for it risks creating a culture whereby appropriate articulation of the supervision and development needs of tutors becomes silenced by fears of being exposed as unable to cope with the demands of the job. 
Gleeson and Knights (2006) see the potential for a shift from professionalism (structure) to professionality (agency), which would enable practitioners to move from managerial accountability towards an ethic of responsibility. Hoyle and John (1995) define professionality as a quality, which embodies skill, knowledge and competences required to make effective pedagogical judgements, which practitioners should be free to make based on the needs of students. Key components in developing professionality are the processes of individual and collaborative reflection, both in and on practice, in order to inform effective judgements, and the development of a set of professional ethics. It is difficult to see how ideas for collective personal and professional development could be taken forward without an institutional commitment to releasing time and resources, and a recognition that such development is essential for tutors' safe and effective working as they undertake a variety of roles including learning and teaching activity, bureaucratic and management tasks, and supporting students.

\section{Summary and Conclusions}

Research has demonstrated the essence of emotion work in learning and teaching in higher education, and the fact that such work is not a recent phenomenon. This indicates a professional and ethical requirement on the part of institutions to consider how tutors can be supported to develop skills in this area. It could be argued that the 'widening access' agenda has encouraged more explicit engagement with the support needs of students, and it is to be hoped that post-Dearing engagement with the scholarship of learning and teaching in higher education will incorporate ethical and emotional themes.

In recognising and acknowledging the existence of emotion work in student support, we can look to the literature on supervision and training in the helping professions for models of professional support and development. Whilst reflective practice features strongly in professional development frameworks such as the Post Graduate Certificate in Learning and Teaching in Higher Education, there remains a need to encourage a cultural shift in what is recognised and articulated through the reflective process. The literature on professional display rules highlights that managerialism 
and bureaucratic monitoring might discourage practitioners from openly acknowledging emotional vulnerability and 'burnout' for fear that this might reflect badly on their professional capabilities. This is likely to have been exacerbated by reference to therapeutic pedagogy, underpinned by the idea of a therapeutic turn whereby students and tutors are caricatured as emotionally dependent individuals.

The contemporary climate of work intensification has had implications for the emotional well-being of higher education practitioners which are, in part, explained by the lack of discursive space available for collective reflection on practice issues. The literature from the helping professions emphasises the need to debrief and discuss ethical and emotional issues. Whilst institutions might consider incorporating the more technical skills of emotion work into models of staff development, the need to make available time and space for discussion in communities of practice, within a professionality model, should also be viewed as an essential staff development resource.

The concept of the therapeutic turn suggests that tutors have a propensity to become therapists rather than educators, and risks portraying tutors as hapless individuals who consider themselves in need of therapy in order to cope with the emotional demands of their inappropriate therapeutic role. In contrast, my research findings indicate awareness amongst many tutors that there are role boundaries with which they struggle because they have not been appropriately prepared for their roles. There is also awareness amongst many tutors that they are not appropriately supported in undertaking the emotion work associated with developing appropriate learning relationships with students. There is a clear indication that tutors make use of relationships with colleagues as a means of support for the more challenging aspects of emotion work. There is also an expressed need for staff development and, in some cases, professional supervision to ensure safe and appropriate working and establishment of professional boundaries. The emphasis is on professional agency and the need to address skills and knowledge deficits rather than a need for therapeutic intervention.

My survey respondents have offered valuable evidence of the need for reform. The emphasis on dialogue with colleagues indicates the appropriateness of a 
professionality model of professional and ethical development, rather than a managerial model. It would appear that work intensification is affecting the availability of collective discursive space, however. If institutional change is to be achieved, tutors need to find a collective voice to make institutions take notice of their legitimate concerns, for as Clegg (2004: 323) points out, the achievement of radical change 'depends on recognising the possibility that as collective agents we can do something to change the conditions which continue to generate profound injustices and inequalities'.

We must act, not only to make gains in staff development and support of tutors, but also to ensure that emotion work is located as an essential element of unified learning, rather than a marketing tool to ensure the management of student retention and satisfaction with the curriculum and the institution.

\section{References}

Beard, C; Clegg, S and Smith, K (2007) 'Acknowledging the affective in higher education' British Educational Research Journal 33 (2): 235 - 252

Brady, J; Healy, F; Norcross, J and Guy, J (1985) 'Stress in Counsellors: An Integrative Research Review' Service' in Dryden, W (ed) The Stresses of Counselling in Action London: Sage

Brockbank, A and McGill, I (2006) Facilitating Reflective Learning Through Mentoring and Coaching London: Kogan Page

Carroll, M and Walton, M (1997) 'Introduction' in Carroll, M and Walton, M (eds) Handbook of Counselling in Organizations London: Sage

Centre for Research in to Emotion Work (online) 'About CREW' available at http://www.brunel.ac.uk/about/acad/bbs/research/centres/crew/about accessed $28 / 12 / 07$

Clegg, S (2006) 'The Problem of Agency in Feminism' in Gender and Education 18 (3): 309-324 
Crossman, J (2007)' The role of relationships and emotions in student perceptions of learning and assessment' Higher Education Research and Development 26(3): 313-327

Earwaker, J (1992) Helping and Supporting Students Buckingham: SRHE and Open University Press

Easton, S and Van Laar, D (1995) 'Experiences of Lecturers Helping Distressed Students in Higher Education' British Journal of Guidance and Counselling 23 (2): $173-178$

Ecclestone, K (2004) 'Learning or Therapy? The Demoralization of Higher Education' British Journal of Educational Studies 52 (2)

Ecclestone, K; Hayes, D and Furedi, F (2004) 'Knowing me, knowing you: The rise of therapeutic professionalism in the education of adults' in Studies in the Education of Adults 37 (2)

Ecclestone, K and Hayes, D (2009) The Dangerous Rise of Therapeutic Education London: Routledge

Fineman, S (2003) Understanding Emotion at Work London: Sage

Fisher, C and Ashkanasy, N (2000) 'The Emerging Role of Emotions in Work Life: An Introduction' Journal of Organizational Behavior 21(2) : 123-129

Furedi, F (2004) Therapy Culture: cultivating vulnerability in an uncertain age London: Routledge

Gleeson, D and Knights, D (2006) 'Challenging Dualism: Public Professionalism in 'Troubles' Times Sociology 40 (2) : 277-295

Grant, A (2006) 'Personal Tutoring: A system in crisis?' in Thomas, $L$ and Hixenbaugh, $\mathrm{P}$ (eds) Personal Tutoring in Higher Education Stoke on Trent: Trentham Books

Habley, W (2000) 'Current Practices in Academic Advising' in Gordon, V; Habley, W and Associates Academic Advising: A Comprehensive Handbook San Francisco: Jossey Bass

Hawkins, P and Shohet, R (2007) Supervision in the Helping Professions (third edition) Maidenhead: Open University Press 
Hochschild, A (2003) The Managed Heart (twentieth anniversary edition) London:

University of California Press

Hoyle, E and John, P (1995) Professional Knowledge and Professional Practice London: Cassell

Kreber, C; Klampfleitner, M; McCune, V; Bayne, S and Kottenbelt, M (2007) 'What Do You Mean By Authentic? A Comparative Review of the Literature on Conceptions of Authenticity in Teaching' Adult Education Quarterly 58 (22) : 2243

Lawrence, D (2000) Building self-esteem with adult learners London: Paul Chapman Publishing

Macfarlane, B (2004) Teaching With Integrity: the ethics of higher education practice London: Routledge

Marr and Aynsley-Smith (2006) 'Putting Students First: Developing Accessible and Integrated Support' in Thomas, L and Hixenbaugh, P (eds) Personal Tutoring in Higher Education Stoke on Trent: Trentham Books

Morris, J and Feldman, D (1996) 'The Dimensions, Antecedents, and Consequences of Emotional Labor' The Academy of Management Review 21(4): 986-1010

Mortiboys A (2002) The Emotionally Intelligent Lecturer London: SEDA

Newman, M (2008) 'Infantalised Students and Staff Rapped' in Times Higher Education 12/6/2008

Ogbonna, E and Harris, L (2004) 'Work Intensification And Emotional Labour Amongst UK University Lecturers: An Exploratory Study' Organization Studies 25(7): 1185-1203

Owen, M (2002) ' 'Sometimes You Feel You're in Niche Time' : The personal tutor system, a case study' Active Learning in Higher Education 3(1) 7-23

Rogers, C (1980) A Way of Being New York: Houghton Mifflin

Simon Frank, K (2000) 'Ethical Considerations and Obligations' in Gordon, V; Habley, W and Associates Academic Advising: A Comprehensive Handbook San Francisco: Jossey Bass 
Stearns, P and Stearns, C (1985) 'Emotionology: Clarifying the History of Emotions and Emotional Standards' The American Historical Review, 90, (4): 813-836

Stearns, P (1989) 'Social History Update: Sociology of Emotion’ Journal of Social History 22 (3): 592-599

Tholstrup, M (1999) 'Supervision in educational settings' in Carroll, M and Holloway, E (eds) Counselling Supervision in Context London: Sage

Walker, M (2002) 'Pedagogy and the Politics and Purposes of Higher Education' Arts and Humanities in Higher Education 1 (1) : 43-58

Wilkins, P (1997) Personal and Professional Development for Counsellors London: Sage

Wootton, S (2006) 'Changing practice in tutorial provision within post-compulsory education' in Thomas, L and Hixenbaugh, P (eds) Personal Tutoring in Higher Education Stoke on Trent: Trentham Books 